\title{
NOTE ON TARSOPHLEBIOPSIS MAYI TILLYARD
}

\section{(ODONATA : TARSOPHLEBIIDAE)}

\author{
By Lt. Col. F. C. Fraser, I.M.S., Retd. \\ Bournemouth, England
}

I wish to correct a serious error made by the late Dr. R. J. Tillyard when describing his Tarsophlebiopsis mayi Tillyard $^{1}$. I am indebted to the Curator of the Sedgwick Museum, Cambridge University, for the opportunity of reexamining this very interesting fossil wing, an examination which convinces me that we are not dealing with a fore wing and a hind wing as Tillyard supposed, but with the right and left fore wings. Tillyard was no doubt swayed by the fact that the impression of the supposed hind wing is pigmented whilst that of the fore wing is not so; he also based his opinion on what he thought to be a greater divergence of the origins of Rii (Mi--ii) and IRiii ( $M s$ ), a divergence which seems to me to be identical in the two impressions. His greatest error, however, is his statement that the fossil shows unspecialized antenodals, which in so archaic a wing is absolutely impossible. It was to prove this latter point that I requested a loan of the specimen and found after my re-examination that the two primary antenodals were indeed present. By making careful sketches of the portions of the wing to the same scale and then making a combined tracing of the two, I found that the various longitudinal veins ran in smooth continuation of one another and that they were obviously both portions of a forewing, the left and right of the insect under examination. Some differences were also found in the anal area of the wing, where only two cross veins can be seen running between $\mathrm{CuA}$ and $\mathrm{CuP}$ and only four in the cubital space. The slight reticulation in the distal part of this space shown by Tillyard appears to me to be due to foreign matter or artefacts. The primary antenodals are the 3rd and 5th from the base of the wing. The reticulation posterior to the anal vein is of three rows of cells, not a network as shown

11923, Geol. Mag., 60: 146-52, 1 pl., 3 figs. 


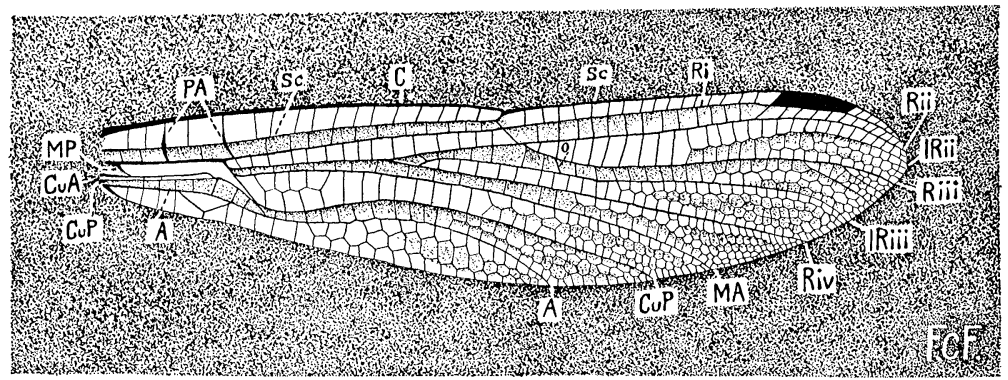

Fig. 1. Reconstruction of fore wing of Tarsophlebiopsis mayi Till. (Tillyardian notation employed).

by Tillyard. The supposed fragment of "the basal posterior margin of a hindwing" fits into the area posterior to the anal vein in the right fore wing. After making these corrections, I have been able to reconstruct a complete fore wing.

NYLANDERIA MYOPS (MANN), NEW COMBINATION (HYMENOPTERA: FORMICIDAE). - The small-eyed Cuban Prenolepis of Mann is placed in Nylanderia to follow the modern classification of these groups. Weber has described a species troglodytes, also from Cuba, supposing it to differ from myops "in distinctly larger size and in the shape of the petiole." Direct comparison of three syntypes of each of these forms now in the Museum of Comparative Zoology shows a slight average size difference, but an absolute overlap exists even in this minute sample. Mann's cited measurements are too low, and could not have been made from a stretched-out specimen. Head and petiole shapes in these delicate specimens vary widely, due to warping and buckling upon drying out of the alcohol. Weber apparently refers to such differences, although these are not clearly seen in the types before me. Formal synonymy follows. Prenolepis myops Mann, 1920, Bull. Amer. Mus. Nat. Hist., 42: 432, worker, female, male. Type loc.: Mina Carlota, Sierra Trinidad. 

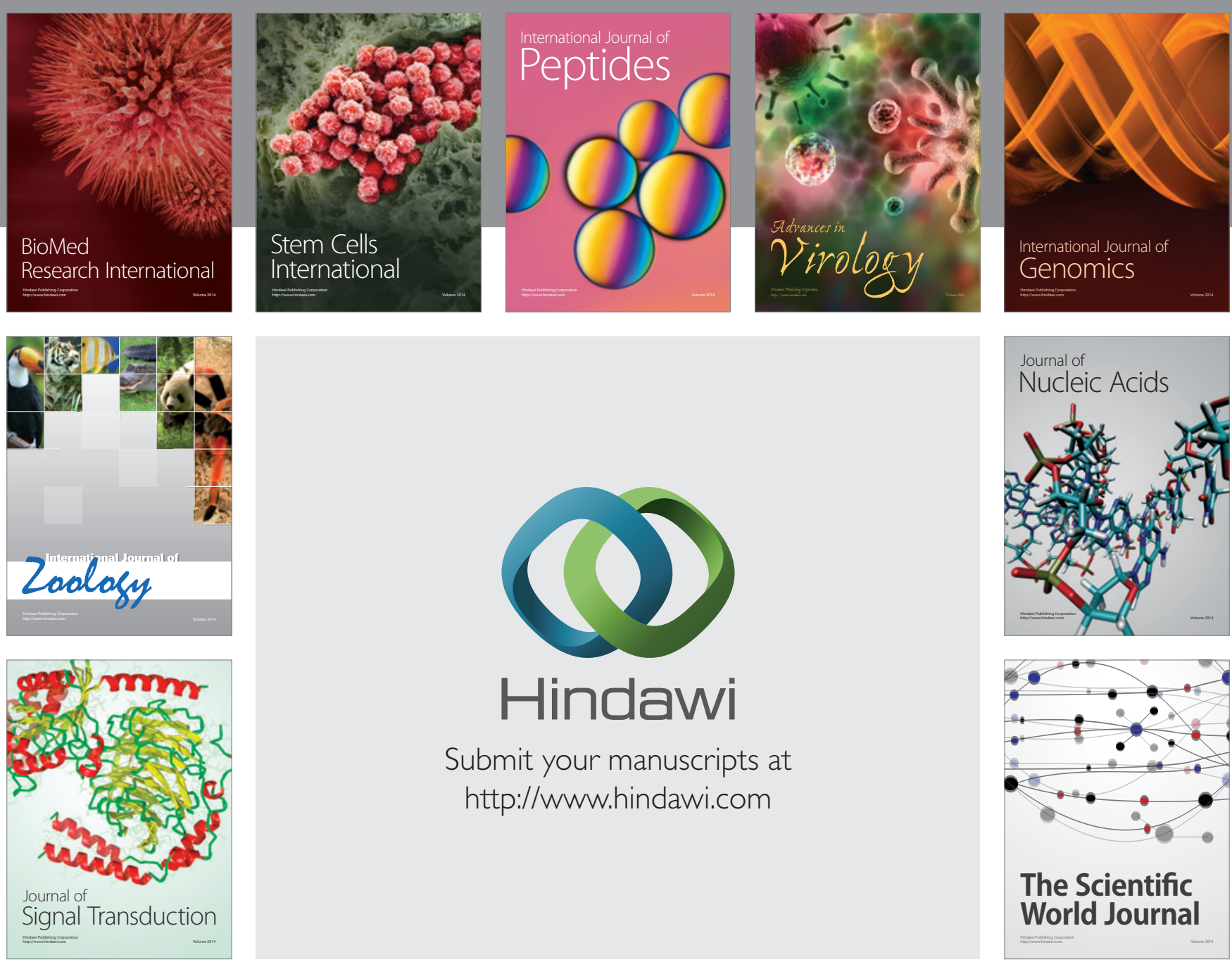

Submit your manuscripts at

http://www.hindawi.com
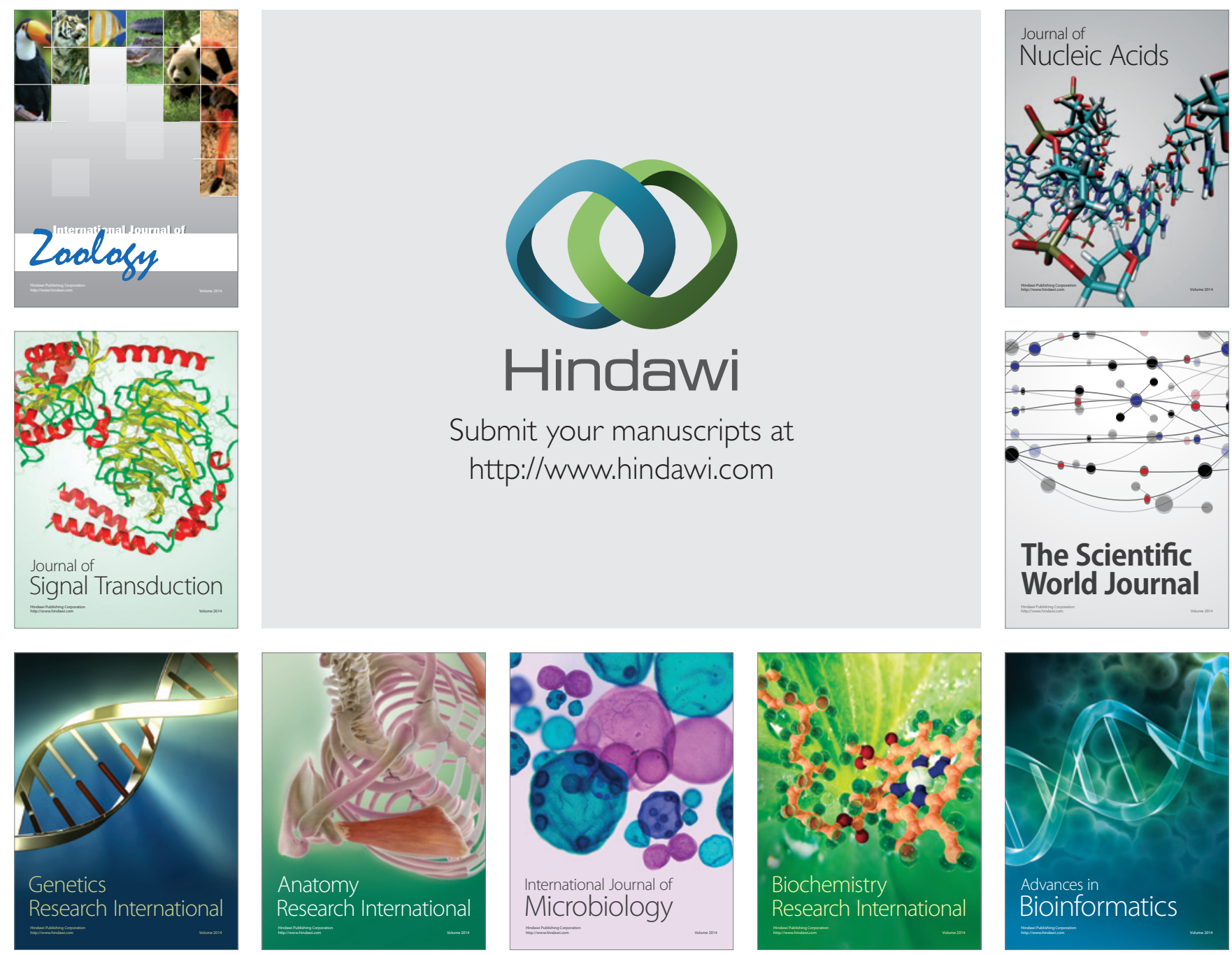

The Scientific World Journal
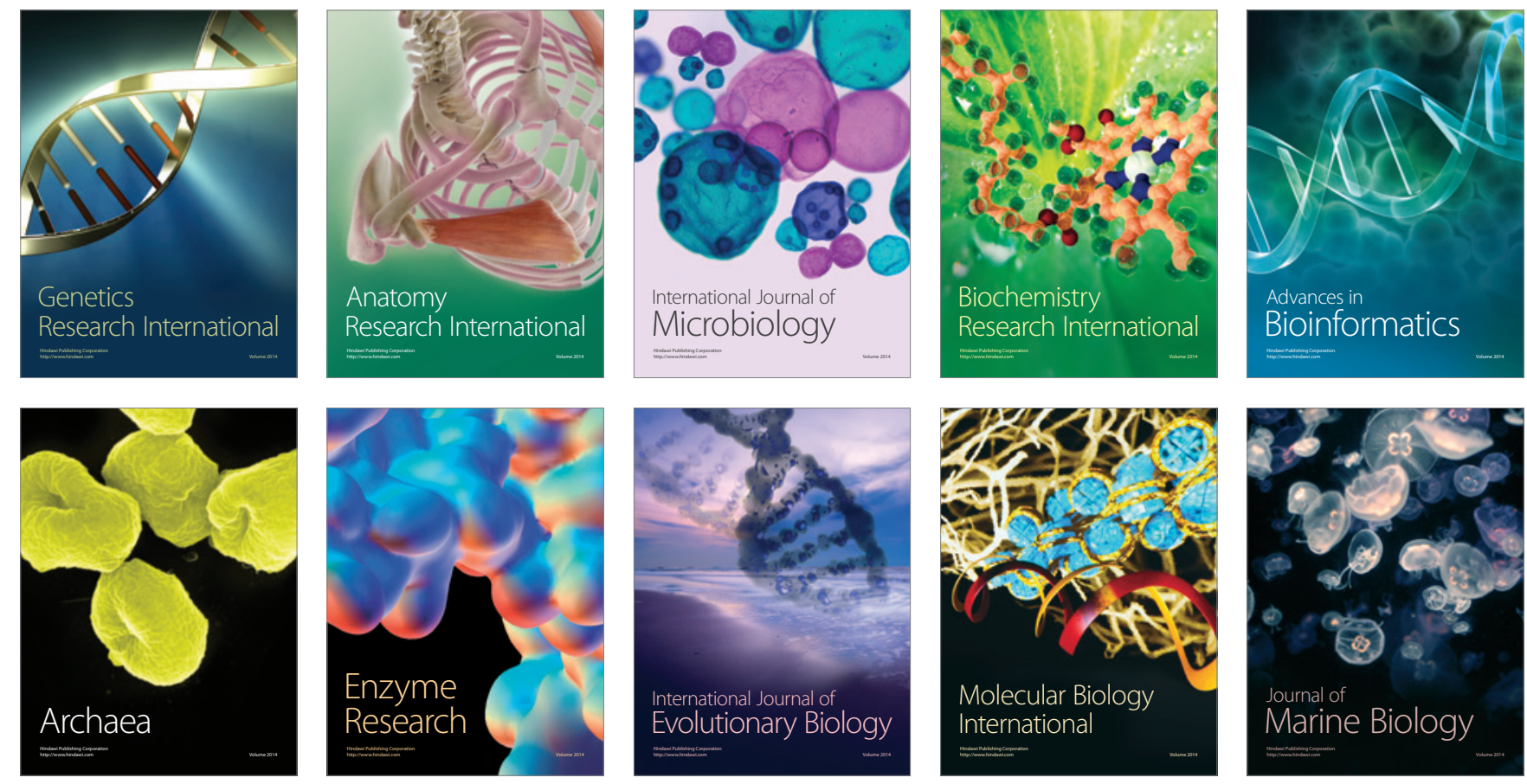